\title{
La fama póstuma de Quevedo en los paratextos de sus obras impresas y en la biografía de Pablo de Tarsia
}

\author{
Manuel Ángel Candelas Colodrón \\ Universidade de Vigo \\ mcande@uvigo.es
}

Recepción: 05/05/2016, Aceptación: 10/01/2017, Publicación: 22/12/2017

\section{Resumen}

La fama póstuma de Quevedo es una construcción heterogénea que procede de varias instancias: este trabajo se limita a describir el modo en que se proyecta la imagen del autor mediante los paratextos de las obras impresas en el siglo XVII y comienzos del xVIII (16451726) y mediante el relato que el historiador Pablo de Tarsia traza de su vida.

Palabras clave

Quevedo; Tarsia; paratextos; canon; Parnaso

\begin{abstract}
The posthumous reputation of Quevedo in the paratexts of his printed works and in the biography of Paul of Tarsus

The posthumous fame of Quevedo is a heterogeneous construction that proceeds from several instances. This article describes how the author's image is portrayed in the paratexts of his printed books in the seventeenth and early eighteenth centuries (1645-1726) and through the narrative that the historian Paul of Tarsus constructs of his life.
\end{abstract}

Keywords

Quevedo; Tarsus; paratextos; canon; Parnassus 
Tenía Bruto estatua, mas la estatua no tenía Bruto hasta que fue simulacro duplicado de Marco y de Junio. No pusieron los romanos aquel bulto en el Campidoglio tanto para imagen de Junio Bruto, como para consejo de bronce para Marco Bruto.

(Marco Bruto, Francisco de Quevedo)

Es mi propósito describir la forma en que se construye la fama de Quevedo, desde su muerte hasta la aparición del Diccionario de Autoridades, ${ }^{1}$ a partir de dos aspectos: los paratextos de las sucesivas ediciones impresas que fueron publicadas a lo largo de ese periodo y la Vida de Quevedo escrita por Pablo de Tarsia en 1663. Tal análisis, obligadamente parcial, no agota en absoluto la arquitectura de su imagen póstuma; faltan por consignar, entre otros muchos modos de la edificación de su imaginario, la difusión de sus obras en forma manuscrita, las traducciones de sus textos a otras lenguas, las opiniones de otros eruditos durante esos años o las fórmulas imitativas que permiten ponderar su presencia en el campo literario del siglo Xvir. En una ideal descripción de la fama póstuma de Quevedo deberían conjugarse todos ellos, de forma necesariamente compleja: en este trabajo me limito a los discursos que adornan las publicaciones impresas, con el complemento de la biografía de Tarsia en plena producción editorial quevediana.

\section{Enseñanza entretenida. El Parnaso español}

La primera publicación impresa después de la muerte de Francisco de Quevedo es la de Enseñanza entretenida y donairosa moralidad, de 1648, a cargo del librero Pedro Coello. ${ }^{2}$ En la dedicatoria, destinada a Pedro Pacheco Girón, del Consejo de su Majestad en el Supremo de Castilla, el mercader de libros, entre las poco menos de dos páginas, escribe:

injusta y desagradecidamente procediera yo, si faltara a tanta deuda de reconocimiento y no dedicara a V.S. esta impresión cuando este espańol famoso deberá a

1. Tomo esta referencia temporal porque es en el diccionario académico donde la recepción quevediana alcanza uno de sus cúlmenes, en forma de hegemonía léxica, si atendemos a los datos de su autoridad en la ejemplificación de las voces presentadas: Guillermo Rojo (2014) computa la presencia de los autores en el Diccionario y llega a la conclusión de que Quevedo es el autor más citado de todos los volúmenes y sus Musas, la tercera obra en importancia del conjunto tras el Quijote y la Nueva recopilación de leyes del Reino.

2. En puridad, en 1646 sale una reedición a cargo del mercader de libros Tomás Alfay de la Introducción a la vida devota y de La cuna y la sepultura, dirigida a Catalina de Salcedo y Tapia, mujer de Gregorio de Tapia que aparecerá en ulteriores dedicatorias; en 1647, una reedición de la Política de Dios en Varsovia; y en 1648, otra del Marco Bruto sobre la princeps de 1644. En ellas no hay mención explícita a la muerte de Quevedo ni tampoco a la posible fama que pudiera otorgársele tras su fallecimiento. 
V.S. principalmente su memoria; y, siendo así, que poniendo su ilustrísimo nombre en su principio, tendrá la protección toda que puede necesitar y juntamente honor sumo y calificación, con que quede estimable en el concepto común de los naturales y de los extranjeros, dando así ocasión a que todos celebren que, cuando los sujetos mayores de la monarquía parece que olvidan el aprecio de los ingenios aventajados, hay uno superior que los honra y anima.

No es fácil descifrar la referencia a «los sujetos mayores de la monarquía», pero parece factible un reproche que revela una de las marcas constituyentes de la fama quevediana a lo largo del tiempo: la incomprensión, la ingratitud o los obstáculos a los que tuvo que enfrentarse, fuesen estos o no falsos, veraces o simplemente exagerados para una edificación canónica del poeta. Están próximos en este año de 1648 los ecos de sus últimos lances políticos, pero no deja de resultar significativo este primer rasgo en la pintura del autor, ya que asomará en formas laudatorias en sucesivas semblanzas de su figura.

El texto de Pedro Coello incide en la idea básica de restauración y restitución de los textos quevedianos ${ }^{3}$ y anuncia la publicación inminente de sus composiciones poéticas. Interesa aquí indicar cómo, al tiempo que se presenta la colección, se institucionaliza la búsqueda de un patrón de opera omnia y se hace pública la necesidad de completar bajo cualquier auspicio el conjunto, presentado como perdido o como usurpado. El carisma del autor se conforma con la idea de reunir su desperdigada producción: el mero hecho de resaltar un proceso in fieri, en el que no falta una narración con obstáculos o enemigos que ocultan o no ceden los materiales que obran en su poder, contribuye a crear unas altas expectativas sobre la magnitud elevada del escritor y a otorgar valor insustituible a la transmisión de su obra.

En ese mismo año de 1648 aparece la edición de sus poemas bajo el título Parnaso español. En otro lugar, hago repaso crítico de los preliminares eruditos de González de Salas, el editor y comentarista de su obra poética. ${ }^{4}$ No me detendré en detallar lo que allí aparece, pero sí en recordar que en las prevenciones al lector se esfuerza en destacar el carácter ejemplar de buena parte de su poesía (en especial la procedente de la musa satírica romana) y en exculpar la derrota más burlesca de otras opciones, con mucho de palinodia ficticia, habida cuenta del cuerpo abundante de los versos jocosos. Aunque es el propio Salas quien se atribuye buena parte de la expurgación sobre el conjunto de su obra, es notoria la voluntad de mejorar la imagen quevediana con la insistencia en la natura-

3. Jaime Moll (1988) explica los pormenores de las ediciones de obras completas quevedianas a lo largo del siglo xviI. Remito a su trabajo para los entresijos comerciales e intereses editoriales de los distintos libreros, que permiten complementar el interés primario de analizar los prolegómenos de estas obras como edificadoras de la imagen (más o menos retórica) de Quevedo.

4. Véase Candelas Colodrón (2003). 
leza edificante de sus textos, con el encomio de su ingenio y conocimiento de lenguas y con el constante parangón de sus propuestas poéticas con los autores clásicos de la literatura grecolatina. La iconografía que acompaña al volumen, estudiada con notable y exhaustiva profusión, ${ }^{5}$ constituye la parte más obvia del proceso de canonización quevediana, con Quevedo colocado en el centro mismo del monte Parnaso, coronado por el mismo Apolo.

La edición del Parnaso de 1648 conoció numerosas reediciones a lo largo del siglo XVII y principios del XVIII. En 1649 dice publicarse en la imprenta del Hospital Real de Zaragoza ${ }^{6}$ y en 1650 aparece una nueva edición corregida, bajo la supervisión de un tal Amuso Cultifragio, seudónimo incógnito, responsable de la edición, en la que se suprimen numerosas aclaraciones y comentarios de González de Salas. La historia de este volumen de poemas es bien conocida: la bibliografía que la describe es extensa, ${ }^{7}$ pero conviene señalar a nuestro propósito que el Parnaso español irá saliendo a partir de ahora asociado al resto de las obras quevedianas. La edición de 1650 sale justo después de que se publiquen la Primera y la Segunda Parte en 1649 y 1650 por Pedro Coello y Diego Díaz de la Carrera. La edición de 1659, de Mateo de la Bastida en la imprenta de Pablo de Val, ${ }^{8}$ con dos emisiones, se publica de inmediato tras la reedición de la Primera y de la Segunda Parte de las Obras del propio Mateo de la Bastida, esta vez a cargo del impresor Melchor Sánchez, con privilegio de 17 de junio de 1657.

El monopolio provisional de Mateo de la Bastida sobre el conjunto de la obra quevediana puede verse como un negocio comercial más o menos buscado por su rendimiento económico y, por tanto, alejado de cualquier determinación cultural o literaria, pero no sería justo apartar del todo el propósito implícito de reunir, de acaparar, de restaurar, de restituir e incluso de controlar todo el proceso de emisión de la obra quevediana. Tal unificación editorial (obligada administrativamente por la aplicación judicial de los privilegios y las licencias) va acompañada por el deliberado uso de la misma dedicatoria para protección al duque de Medinaceli, de la misma censura presentada el 22 de junio de 1644

5. Destaco de esta bibliografía abundante el trabajo de Julio Vélez-Sainz (2006) y el número monográfico editado por Carlos Gutiérrez para La Perinola (2011) sobre recepción quevediana como fundamentales. Los trabajos recientes sobre el proceso canonizador revelan el carácter relevante del macrotexto quevediano en la construcción del Parnaso como lugar de encuentro poético: véanse al respecto el volumen editado por García Aguilar (2009a) sobre los modelos editoriales de poesía tardobarroca y su monografía (2009b) sobre la bibliografía material de este siglo.

6. Jaime Moll la considera una edición falsificada la impresa en la imprenta de Francisco de Lyra en Sevilla (1980: 48-49).

7. Alfonso Rey (1992: 40-62) hace relación de todas estas ediciones. Habría que añadir la lisboeta de 1652, de Craesbek, que, según Alfonso Rey, está hecha «a plana y renglón sobre la de 1649» (1992: 44).

8. Mateo de la Bastida es el vendedor, como el de las otras ediciones de los años pecedentes: «Segunda vez, Señor Excelentísimo, busca el Parnaso español de D. Francisco de Quevedo Villegas el patrocinio de V.E.», le recuerda en la dedicatoria. 
con Quevedo aún vivo y hasta de los mismos títulos genéricos que recogen las licencias, Obras divinas y humanas. Esta uniformidad, probablemente debida a un comprensible ahorro de esfuerzos, complementa la noción de construcción dirigida de la fama quevediana, no dejada al albur de la utilización ajena. La concentración de poder editorial, como resultado de los ajustes legales, canaliza y dirige la proyección de la posible fama quevediana.

Conviene notar que los lectores de esas nuevas ediciones y reediciones recibirán las composiciones quevedianas bajo la divisa parnasiana y conforme a las disposiciones del comentarista quevediano, de acuerdo o no con las indicaciones de Quevedo. La autorización de Salas, como dispositivo sancionador de un clasicismo, va a quedar algo rebajada en las sucesivas ediciones en lo que respecta a su presentación y natural condicionamiento erudito, pero conserva su valor esencial como agente intermediario en la lectura de Quevedo. El corpus de los poemas quevedianos se instituye sobre un horizonte de opera omnia inconclusa, que debe tener su natural continuación: la llegada prometida de una segunda parte, que se demora más de veinte ańos, constituye para buena parte de los lectores un elemento sustancial de la comprensión de su producción impresa.

En todo caso, leer a Quevedo en estos años centrales del siglo XVII será posible (al margen de las opciones manuscritas) bajo la forma material de un libro (de cuarto, además) recopilatorio, ordenado y organizado como summa totalizadora, en el que la prosa burlesca, los discursos severos y las composiciones en verso comparten un mismo espacio, con lo que esto puede resultar de determinante en el modo de lectura y de recepción quevedianas. Añádase a este particular lo que señala Jaime Moll (1988) sobrela edición de 1658 delas Obras de Quevedo:que no habrá variación en la estructura de esos dos tomos a lo largo del tiempo, lo que le confiere a tal edición una impronta fundamental en la recepción ulterior de la obra quevediana. No interesa en este caso la distribución en sí misma, sino la forma en que los lectores quevedianos acceden a sus textos, en forma orgánica bajo el marco de su autor, presentado además con efigie reveladora, al margen de géneros, estilos o modalidades discursivas.

\section{La fortuna con seso y La hora de todos. Virtud Militante. Política de Dios}

En el año de 1650 se publica en Zaragoza, con Roberto Duport en la imprenta de Pedro Lanaja, La fortuna con seso y La hora de todos, la primera edición de esta obra quevediana, con varias emisiones ese mismo ańo, fruto tal vez de su éxito. ${ }^{9}$ La solución arbitrada para esta editio princeps es la de atribuirla a un tal Rifroscrancot Viveque Vasgel Duacense, anagrama de Francisco de Quevedo y Ville-

9. Remito los pormenores de su historia textual a la introducción de Lía Schwartz (2003) a su edición de La fortuna con seso. 
gas, y presentarla como traducida del latín por Esteban Pluvianes del Padrón, natural de la villa de Cuerva Pilona, un anagrama probable de Barcelona. El extremo de este juego de ocultaciones hace que sea a este mismo Esteban a quien se le concede licencia, con Roberto Duport como muñidor, de esta edición.

¿Era necesaria esa disimulación con Vincencio Juan de Lastanosa como destinatario de la dedicatoria? Cinco años después de la muerte de Quevedo, su nombre aparece enmascarado cuando se trata de presentar una fantasía moral, incluso con todas las licencias imprescindibles. Las ediciones ven la luz bajo la jurisdicción del mismo reino de Aragón en el que Quevedo había visto impresas las obras que le ocasionaron algunas incomodidades con la arbitrariedad de las denuncias inquisitoriales. A la luz de los paratextos comentados de 1648, este disfraz se antoja casi obligado para preservar una fama que comienza a edificarse con los mimbres morales y religiosos. Las suposiciones razonables sobre la omisión de pasajes más molestos y comprometidos en esta edición de Zaragoza con respecto a la tradición manuscrita puede ser además dato de relieve sobre la necesidad de cuidar esa imagen..$^{10}$ No sería inconveniente recordar aquí que fue en Huesca donde firmó (falsamente) la redacción de su Chitón de las tarabillas, escrito bajo anonimia o bajo la seudonimia del Licenciado Todo lo sabe. ${ }^{11}$ En todo caso, la máscara con anagrama y la intermediación lúdica de un traductor, propio o, al menos, cercano al género satírico — se ignora si idea del propio Quevedo antes de su muerte o estratagema del editor-, permite conjeturar una salvaguarda de cierto perfil severo de su personalidad autorial.

Los herederos de Pedro Lanaja imprimen al año siguiente, en 1651, Virtud militante. La censura, firmada en el mismo año por Bartolomé Foyas, "por comisión del excelentísimo señor conde de Lemos, Virrey Capitán General de este reino de Aragón», parece ignorar la muerte de Quevedo, a juzgar por el uso algo particular del verbo en presente:

antes bien he notado, como digno de toda alabanza, que, siendo el autor caballero secular, de capa y espada, se muestra muy versado en la Sagrada Escritura y leído en las doctrinas de los santos Padres de la Iglesia y discurre en las materias de su asunto altamente, con estilo grave y agudo.

En la dedicatoria del librero Robert Duport al señor Gregorio de Tapia y Salcedo, caballero de Santiago y fiscal de su Majestad, se apunta la idea de que es obra nueva:

10. Véase al respecto de las relaciones entre la tradición manuscrita y la impresa el artículo de James O. Crosby (1990).

11. En 1651 saldrá una edición también en Zaragoza a cargo de Pedro Escuer en las prensas de Juan de Ybar, con el título de La hora en la que sí aparece el nombre de Quevedo como autor de la sátira, aunque se mantiene el seudónimo, una vez pasada la novedad y el éxito del ańo anterior. En esta la que la dedicatoria está destinada al marqués de Mortara, virrey y capitán general de Cataluña. 
viendo que faltaba esta piedra, la más preciosa de la arquitectura de sus escritos que corren impresos en un volumen, determiné hacer este beneficio a España dando a la estampa este, no sé si el último pensamiento póstumo suyo.

El dominio jurídico y político en el que aparece no es el de Castilla, como se apresura a comentar Duport («méritos de Castilla saben gozar los aplausos debidos en Aragón»), sino el del reino aragonés, en donde años atrás Quevedo vio publicados sus Sueños, ahora ya algo lejanos en el tiempo. Por un lado, se ciega su nombre para La fortuna con seso y, por otro, se destaca para esta Virtud militante, pieza central de su discurso doctrinal: la primera, destinada a un humanista como Lastanosa, un mecenas que participa en la misma órbita erudita que Quevedo; ${ }^{12}$ la segunda, a un representante del poder, al mismísimo virrey y capitán general del reino. Y todo ello, a casi veinticinco ańos más tarde de su muerte, donde parece extrańa y al tiempo sintomática esta forma particular de atención a la obra quevediana.

En 1655 sale la edición de la Política de Dios por primera vez completa, con sus dos partes. Es Pedro Coello quien la saca y la adorna con ilustración de Marcos Orozco. Está dedicada al Duque de Medinaceli, como la obra poética. Las censuras son de Pedro Ruiz de la Escalera y Quiroga (de 1655), caballero de Calatrava y caballerizo de la reina Nuestra Señora, y de Gerónimo Prado, Provincial de Clérigos Menores, de 1652. El primero avisa en nota marginal impresa de la segunda parte del Parnaso españoly alaba a Quevedo con palabras que en modo tópico pero significativo resaltan la índole ejemplar de sus discursos:

desta fuente divina [la sagrada escritura] se conducen los cristales desatados en la prosa desta Política; atados a los números altamente, ya D. Francisco condujo otros de la humana de Castalia a Castilla para honesta recreación al ocio, dedicada al trabajo de su estudio, para el fruto de quien la leyere, usándola como bebida.

Gerónimo Prado, en la página siguiente, celebra el estilo de Quevedo con parecido tenor encomiástico: «es superior, dulce, llano, puro, proprio, elegante, decoroso y lleno de religión, tan parecido al de sus heroicas obras que al primer rasgo se da a conocer que es suyo». No disimula el Provincial el préstamo de las palabras que Lorenzo van der Hammen emplea en la edición de la primera parte de 1626 cuando dice que el estilo de Quevedo «es dulce, llano, puro, proprio, elegante y lleno de religión y piedad».

En 1662 sale una reedición de esta Política de Dios completa; en este caso se presenta el privilegio de don Pedro Aldrete como heredero, despachado el 17 de

12. Trevor J. Dadson (2011: 29) recuerda que entre los inventarios de libros que investigó solo seis mostraban un interés particular por la poesía: el de Vincencio Juan de Lastanosa era uno de ellos, con 27 títulos. El propio Dadson apunta que Lope de Vega, Quevedo y Luis de Góngora son los «poetas más populares». 
junio de 1658: «el cual dicho privilegio tiene hecha cesión a Mateo de la Bastida». La dedicatoria ahora es para Ramiro Felípez Núnez de Guzmán, duque de Medina de las Torres, acompañada de una extensa genealogía escrita por Gabriel Osorio. Es de notar que la presentación de Política de Dios se acompaña ahora de un largo discurso encomiástico que repasa los hechos heroicos de la persona elegida para proteger la publicación del libro. Se confirma además esta práctica del aparato genealógico en la dedicatoria en la tercera vez que se imprime el libro en 1666 desde la Imprenta Real. Esta Politica de Dios conserva la censura de 1655 - incluso con el uso del verbo en un presente que parece no conocer aún la muerte de Quevedo- pero el destinatario es Sancho de Villegas, familiar del propio Quevedo.

Podrá argüirse que esta fórmula pertenece a la tópica del proemio o del panegírico, pero es significativo el esfuerzo por elaborar un relato extenso que preceda al texto quevedesco, con el propósito de canonizar, probablemente a un tiempo, autor y destinatario, no necesariamente con este orden o jerarquía. La incorporación de la genealogía de la persona a la que va dirigido el libro se apreciará también en la biografía de Tarsia, escrita por estos mismos años. La dedicatoria de Tarsia al sobrino de Quevedo ofrece una completa relación de la ascendencia del apellido Villegas y tanto en la biografía como en estas reediciones de la Política de Dios se busca cumplir con la analogía de las galerías de retratos o de bustos de antepasados en los atrios de las grandes casas nobiliarias. Los textos de Quevedo pueden operar como memoria del nombre familiar y, por tanto, como elementos que contribuyen a la glorificación y a la perpetuación de la fama: ${ }^{13}$

pues como dice san Jerónimo en aquella glosa: memoria trae consigo un honroso estímulo de adelantarla con realces de mayores progresos, confesando de sí Quinto Máximo y Publio Escipión, según refiere Salustio, que, cuando ponía los ojos en las imágenes de sus ínclitos antepasados, se les encendía heroicamente el ánimo para emprender nuevas proezas y conseguir por ellas semejantes y público honores. Imágenes son las que presento a V.M en la genealogía de su casa de Villegas.

En 1666 habrá otra reedición de Mateo de la Bastida, con Pablo de Val como impresor. Cuatro ediciones de la Politica de Dios completa se suceden en once años; dedicadas a tres personas distintas: el duque de Medinaceli, el duque de Medina de las Torres y don Sancho de Villegas, quienes, por cierto, sustituyen al mismísimo conde duque de Olivares como destinatario primero de la primera parte publicada en 1626 . El éxito parece más que notable y cabe la sospecha de que se invierte la idea de buscar un protector para la obra quevediana política por la posible utilización del texto quevediano para excusa o pretexto

13. Véase al particular el artículo de Francisco J. Escobar Borrego (2012: 174 y ss) en el que explica con detalle el uso retórico de este topos de las memorias como apología de la nación. En este caso, los textos-monumentos quevedianos sirven como encomio de la estirpe familiar. 
del elogio nobiliario. Mateo de la Bastida se esfuerza en el encomio, propio del protocolo del mecenazgo, pero el discurso quevediano ya parece una ofrenda extraordinaria para la labor retórica.

\section{Vida de Quevedo de Pablo de Tarsia}

En mitad de este relato de la construcción de la figura quevediana dibujada en los paratextos y en los libros impresos, el historiador de Conversano, por entonces ciudad dependiente del virreinato de Nápoles, Pablo de Tarsia, publica una biografía de Quevedo. Lo hace en 1663, aunque un ańo antes parece haberla ya terminado, a juzgar por los preliminares de tal edición. ${ }^{14}$ Su redacción pudo haber comenzado incluso antes, sobre el 1658, cuando él mismo declara que ha visitado lo que él llama el Museo de Pedro Aldrete en el que se conservan documentos y testimonios sobre Quevedo.

La biografía aparece dedicada al propio sobrino de Francisco de Quevedo, Pedro Aldrete, con el argumento ya visto de adornar el portal de su casa nobiliaria con las efigies de sus antepasados: la singularidad es que Tarsia equipara modo metaphorico su libro sobre la vida de Quevedo a una estatua con hornacina que traiga al presente el recuerdo de los hechos célebres de su antepasado. Con un texto del muy leído y, sobre todo, muy consultado libro de los Hechos y dichos de varones ilustres de Valerio Máximo, Tarsia emprende el relato/retrato de Quevedo con la idea de colocarlo en un lugar eminente, a modo de museo familiar del apellido Aldrete:

Es deuda de mi obsequio [...] poner esta imagen delineada con los colores que ha podido alcanzar mi pluma en el patio y primera entrada de su casa, en la cual, habiéndose incorporado la de Don Francisco, por derecho de sangre y de última voluntad, no la puedo dar nicho más suyo en donde sirva de ejemplo a la posteridad, pues a este blanco tiraron los más nobles y más entendidos caballeros de la antigüedad en adelantar el uso comúnmente introducido de tener cada uno en lo más vistoso de sus casas las memorias de sus mayores. (Tarsia 1988: 3v)

Añade a la dedicatoria la habitual genealogía de la familia Aldrete, como parece acreditarse en los preliminares de esta naturaleza, donde se acrecienta la gloria mutua de autor y protector, por vía de una amplia laudatio familiae. Es muy posible que algunos datos que recoge el historiador italiano procedan de la cosecha del sobrino de Quevedo. Pero no es menos cierto que el biógrafo se ha esmerado en recoger con detalle tales precisiones. Es confuso el comentario que el sobrino de Quevedo hará al frente de la Segunda Parte del Parnaso sobre la

14. Sigo la edición facsímil de la edición príncipe de 1663, reproducida por Melquíades Prieto Santiago y prologada por Felipe Pedraza (Tarsia 1988).] No conviene olvidar que durante el siglo XVIII la biografía de Tarsia se incluirá como parte de las obras completa de Quevedo. 
necesidad de mejorar la biografía de su tío, pero el trabajo de Tarsia se presenta muy completo unos ańos antes. Al menos, el propio Tarsia no deplora ausencia alguna en su labor, si bien, en modo retórico, declara brevedad en su discurso y una ulterior redacción ampliada de lo escrito con lo que puedan aportar los lectores insatisfechos con los datos proporcionados.

Alessandro Martinengo (1982) observa, en relación a la fiabilidad o la autoridad del testimonio del biógrafo, que el discurso es una pieza retórica semejante en su dispositio y en buena parte de su contenido al género hagiográfico. No falta, como el propio Martinengo resalta, una mención, aunque de pasada y no muy continuada, a hechos milagrosos post mortem, que, sin duda, contribuyen a una divinización pagana del poeta elevado al Parnaso. Esa modalidad discursiva puede llevar a una sospecha permanente sobre la fidedignidad de los hechos descritos, pero para el propósito de este trabajo es asunto algo más secundario, ya que esa misma canonización, beatificación cuando no casi santificación del escritor español, ofrece un particular imaginario de Quevedo.

Pablo de Tarsia, que lega numerosos textos impresos, parece destacarse en el género histórico: de él son dos historias relativas a Conversano, su localidad natal; uno, dedicado a la virgen de esa ciudad italiana (1648), y el otro, a la propia urbe (1649). Más interesante — aún hoy utilizado por la historiografía moderna - es su relato de la rebelión napolitana de mediados del XviI, que él titula Tumultos de la ciudad y reyno de Nápoles en el año de 1647, publicado en 1670. Una colección de catorce elegías latinas dedicadas a la descriptio urbium de Europa (Europa singulas et praecipuas urbes, 1661), con especial hincapié en Italia y en el llamado reino napolitano, ${ }^{15}$ añade a su perfil humanista un interés por la geografía. Con un curriculum particular de historiador interesado en asuntos propios, accademico ozioso de Nápoles, parece algo extrańa su aplicación a contar la vida de Quevedo. Martinengo apura una admiración indirecta, fruto del buen nombre que Quevedo habría dejado entre los académicos y el ambiente literario napolitano. En tal admiración no debe descartarse una, siquiera secundaria, pretensión de promocionarse a costa de dedicarse a autor canonizable o ya canonizado a las alturas en que Tarsia emprende el relato.

No es baladí conocer la justificación de Tarsia para escribir tal biografía. La lectura de otro de sus textos puede ofrecer ciertas pistas: el Memorial al Rey Felipe $I V(1652)$, en el «que refiere el origen, calidad, casamientos, títulos, estados, dignidades, puestos, privilegios, grandeza, hazañas y servicos del esclarecido linaje de los Aguavivas». La marca genérica de memorial fundamenta la finalidad de su discurso: Tarsia lo escribe con el propósito de defender la inocencia del Conde de Conversano, Giangirolamo II, del que es secretario, que ha sido llamado a

15. El libro posee la particularidad de estar dedicado a Pascual de Aragón, ser editado en Lyon (1661), y ser redactado por los años en que tal vez estuviese escribiendo su libro sobre Quevedo, en 1658. 
Madrid para que dé explicaciones al rey sobre ciertas actuaciones controvertidas en territorios de la Apulia, pertenecientes al virreinato de Nápoles. Escribe para

insinuar los méritos aventajados que ha adquirido en servicio de la corona real y solicitar el premio por ellos y por los de sus ascendientes, tan debido a la persona y casa del conde y también porque vuestra majestad tenga presentes las noticias más individuales y constantes por autoridades, privilegios, instrumentos y otros papeles auténticos sacados de archivos públicos y reales de la ilustre calidad, finezas ejemplares y servicios tan relevantes como los del conde. (Tarsia 1652: 1) ${ }^{16}$

El relato de la biografía de Quevedo tal vez tenga similares intenciones de defensa de una personalidad controvertida, acusada por varios frentes de actuaciones no siempre loables. No es descartable este presupuesto como motor del discurso de Tarsia, pero tampoco debe desdeñarse la posibilidad, para un Abad de una ciudad de la Apulia, historiador erudito, secretario de un noble italiano con graves problemas judiciales con el rey Felipe IV, trasladado a la corte madrileña por tal razón, de obtener, gracias a la tarea de contar la vida de un autor relativamente famoso, una posición o un lugar dentro del campo intelectual y literario del momento. Es difícil discernir si Tarsia ofrece a Quevedo un estímulo para su canonización o si es Quevedo quien mejora en Tarsia su categoría de erudito al ser utilizado como objeto de estudio y atención. $\mathrm{O}$ ambas cosas a un tiempo, en un ejemplo notorio de simbiosis cultural destinada a ocupar en todo caso el centro del terreno literario.

La construcción biográfica de Tarsia presenta un programa definido: el de resaltar la condición profundamente religiosa del protagonista, sujeto a los dictados doctrinales del estoicismo, la riqueza y amplitud de su capacidad intelectual, cifrada en su pericia en diferentes lenguas, en su afición obsesiva por la lectura y en su curiosidad erudita por todo tipo de ciencia, aun la filosofía natural o los detalles de la física. Se extiende, a partir de estas ideas básicas, en desarrollar la imagen de Quevedo como homo politicus, al servicio de la corona austriaca, tanto de sus inmediatos señores en el virreinato napolitano como de los monarcas.

Se defiende la acción de Quevedo en dos episodios controvertidos, vinculados a su tiempo como secretario del duque de Osuna. Se adjunta para uno de los casos (el cohecho en el cobro de los donativos) carta exculpatoria y se añade para el otro, el de la conjuración veneciana, máscara casi jocosa con que librarlo de la vergüenza. El relato maniqueo, propio de las hagiografías, coloca a Quevedo en

16. En el capítulo XII de este MemorialTarsia se refiere cómo el conde de Conversano contribuyó de forma heroica al apaciguamiento de la revuelta de 1647 en Nápoles. Este episodio es clave en la construcción de la genealogía, ya que, al parecer, el conde de Conversano había sido acusado de ciertas deslealtades a la corona y estaba necesitado de una defensa de sus méritos. No cabe una analogía exacta con el objetivo de la biografía quevediana, pero el propósito de escribirla debe obedecer a estímulos si no iguales sí al menos semejantes: los episodios que tienen que ver con su comportamiento político son relatados con indudable intención pro domo sua. 
medio de las intrigas palaciegas, como víctima propiciatoria de un turbio statu quo, del que sale librado por su disposición anímica estoicista, admirable a todas luces. La afinidad con lo expuesto en forma resumida por el sobrino de Quevedo, unos años después en el prólogo de Las tres musas, refuerza la idea de un mismo foco propagandístico, por otro lado, muy eficaz, habida cuenta de su rendimiento futuro en la construcción de la historia ejemplar de Quevedo.

Para la descripción de la obra de Quevedo Tarsia formula una reticencia retórica: se excusa con la capacidad de los libros del autor español de hablar por sí solos. Proporciona una metáfora que incrementa la canonización parnasea: cada libro es un mausoleo que inmortaliza al escritor. Prorroga la tópica expresada en la edición de Salas sobre la abundante producción literaria quevediana y sobre la dificultad de reunirla toda. Aporta en este elogio una singularidad novedosa, que será de utilidad y que funciona como instrumento también de perpetuación canónica: el establecimiento de un catálogo de todas sus obras, basado en lo que ha salido de la imprenta, pero ordenado, con salvedades, con más adecuado criterio temático. Primero Tarsia refiere las de carácter religioso doctrinal, con las biografías de santos; luego las políticas y las satíricas, todas ellas en prosa, para concluir con el Parnaso, del que anuncia continuación inmediata.

Ofrece particular interés su voluntad de dejar constancia de la obra quevediana perdida u ocultada: «diferentes tratados he visto en el Museo de su sobrino Pedro Aldrete de Quevedo y Carrillo, que guarda los rasgos de la pluma de su tío con celo muy debido a la estimación que todos hacen deste varón insigne» (1988: 42). Tarsia señala que Quevedo dejó «de su letra» una lista de obras que deben ser rescatadas: la relación de ellas incluida en la biografía ha podido servir durante siglos de seńuelo a los estudiosos, pero, en el contexto de una biografía canonizadora y aun santificadora, tal vacío no es solo una noticia más, sino una fórmula indirecta para la perpetuación de un canon quevediano que se va configurando de forma perentoria en el tiempo.

En la alabanza de Quevedo Tarsia invierte citas de varios autores contemporáneos que entronizan al poeta. Pero aduce un episodio singular para dar cuenta de la fama inmediata que cobra tras su muerte. Se trata del recibimiento a la entrada de la reina Mariana de Austria en Madrid en noviembre de 1649. ${ }^{17}$ En los aparatos escenográficos que acompañaron a la llegada triunfal, inventados por Lorenzo Ramírez de Prado, ${ }^{18}$ se incluyó un Monte Parnaso y en él, según relata

17. El propio Pablo de Tarsia colaboró en el recibimiento con la escritura de un epitalamio ilustrado con numerosos emblemas que podían servir para el adorno de la ceremonia: Nuptialis currus elogiis ac symbolis apparatum ad hymeneos augustissimo et potentissimo Philippi IV et Mariae Annae Hispaniarum Regg (Zaragoza, 1649).

18. En el Inventario de la librería de Lorenzo Ramírez de Prado (s.l., s. n., s. a: circa 1660) consta casi toda la obra de Quevedo, con varios ejemplares además de ciertos libros, como La fortuna con seso, Virtud militante, las Obras (de 1650 y 1653, duplicada esta) o el Parnaso, uno de los cuales lleva fecha de 1647. Curioso es que en el inventario se incluyan Introducción a la vida devota y La 
Tarsia (26-28), la estatua de Quevedo ocupó lugar eminente. Según la Noticia del recibimiento y entrada de la reina nuestra señora doña Maria Ana de Austria en la muy noble y leal coronada villa de Madrid (1650?), la disposición pretendía reunir a tres grupos de tres poetas españoles: Séneca, Lucano y Marcial, del tiempo de los romanos, españoles a beneficio de inventario; Juan de Mena, Garcilaso y Camoens, "de la anciana edad nuestra»; y Lope de Vega, Góngora y Quevedo, de la más cercana. Las estatuas de todos ellos llevaban carteles con fragmentos de sus obras, alusivos al recibimiento de la reina. A Quevedo le correspondieron los versos «Llevadme, MUSA, que en vano / mis pies lo procuran, pues, / ni aún de mis versos los pies / bastarán sin vuestra mano». Tarsia no comenta más, pero sabemos por la relación que se imprimió que a cada poeta le fue asignada una musa («a quien debiese cada genio la inspiración de sus escritos») y que le tocó a «don Francisco, THALIA, musa jocosa, con una máscara risueña, por empresa: 'Solo a mí toca, sonora, / al nuevo sol hacer salva, / pues hoy toda es risa el alba I y ningún llanto la aurora” (Noticia 1650: 5-12). El écfrasis de Tarsia sobre la arquitectura efímera de los fastos de la monarquía austriaca apunta al mismo lugar de la celebración y entronización del poeta. La hagiografía, como quería Martinengo, se sustenta con la relación de pruebas de la admiración causada en sus contemporáneos y esta concluye con la colocación, cuatro años después de su muerte, en noviembre de 1649, de su estatua en el museo particular del país o del dominio dinástico (nación: si se quiere aventurar una construcción nacionalista en tal propuesta) que visita la nueva reina de España.

\section{Las ediciones de Bruselas}

En los años en que iban saliendo las ediciones de Política de Dios y la biografía quevediana de Tarsia, se vieron publicadas las obras completas de Quevedo en Madrid, por Mateo de la Bastida, en 1658, ya mencionadas, y en Bruselas, por los editores Foppens en el año 1660. En Bruselas el Parnaso pasa a integrarse en el conjunto de obras completas y así aparecen en tres volúmenes: dos de prosa y uno de poesías. El propio Foppens explica la distribución de las obras en el «Prólogo del Impressor al Curioso»:

reduje a tres cuerpos iguales los escritos, que andaban derramados en muchos, de talle, letra y papel diferente. En el orden de las obras, le observé de recoger las más selectas en lo grave y lo jocoso al primer tomo, ańadiendo a La fortuna con seso algunos fragmentos manuscritos que me suministró un curioso; en el segundo las más piadosas y algunas posthumas indiciadas de no ser hijas de la misma pluma,

cuna y la sepultura dentro de las obras en octavo de las sacras; las Obras en prosa, Politica de Dios («en un cuerpo, Madrid, 1655»), la Carta a Luis XIII (1635), la Vida de san Pablo (1644), La fortuna con seso (1650), Virtud militante (1651), entre las políticas y jurídicas; y el Parnaso (1648) junto al Epicteto y Focilides (1634) entre las humanas en letras vulgares. 
pero que por el aire de sus frases y conceptos merecen volar con el mismo aplauso; en el tercero van las poësías.

La institucionalización de la obra quevediana está a punto de sistematizarse, a la espera anunciada de que el resto de la producción poética pueda publicarse en breve. La edición de Bruselas constituye uno de los hitos de la trayectoria impresa de la obra quevediana, ya que supone la caracterización de Quevedo como un autor total, de obra completa, presentada como un conjunto orgánico. La colección aparece dedicada a don Luis Benavides Carrillo y Toledo, Gobernador y Capitán General de los Países Bajos. Francisco Foppens establece una analogía característica del parangón latinizante canónico: el librero se asimila, en su dedicatoria, a Cirilo en su dedicatoria al emperador Teodosio, para proceder a un elogio prolongado hacia las numerosas hazañas del destinatario. La conclusión de tal analogía coloca, pues, la labor literaria de Quevedo como acompańamiento de la actividad heroica de los gobernantes:

Consagren otros lauros y blasones a tan inmortales proezas, que yo lo más que puedo consagrar a V. Excelencia son los libros de un autor, cuyas letras merecen el patrocinio de las armas, por haber defendido ingeniosamente las armas con sus letras. Ninguno más versado en las divinas y humanas que don Francisco de Quevedo, varón incomparable en ciencias y noticias, señor absoluto de la lengua castellana y digno de que V. E. emplee en su lectura aquel afecto con que dice Luciano de Augusto César, que peleaba de día y estudiaba de noche: media inter proelia semper/ stellarum, caelique plagis, superisque vacabat.

En el prólogo al lector, el impresor neerlandés declara poner extremo cuidado en la transcripción de los textos, a pesar de no ser su lengua primera y tener la castellana como aprendida con rigor. ${ }^{19}$ Los censores del libro son los mismos de la edición de 1644 del Marco Bruto, con las convenientes alteraciones sobre los títulos. La iconografía de esta edición magna presenta notable interés. Cuenta con tres láminas: la primera, con el título de Obras de don Francisco de Quevedo

19. Así escribe Foppens en su prólogo al curioso: «No extrañes, oh lector, ver las obras de don Francisco de Quevedo, impresas en Bruselas, corte de los Países Bajos, pues, fuera de que a sus naturales con la anciana y frecuente comunicación de los españoles se les ha hecho muy familiar su lenguaje, en mí se añade el uso y hábito de él, por haber dado en él en mi oficina diversas obras a la estampa, sin pecar groseramente en la lengua ni ofender su elegancia con solicismos. En esta por el respeto que se debe a su esclarecido autor, desconfié de mi cuidado (aunque le puse particular) y busqué personas de toda erudición en el estylo castellano, por cuya mano y estudio corriese la emienda de los yerros. Todos son inevitables y más los de la ortografía y aquellos que se cometieron en la primera impresión del original manuscrito, que han dejado en todas las siguientes tal o cual vez el sentido confuso y imperfecto. Para corregir estos, es menester adivinar lo que quiso decir el autor y habiendo sido tan peregrinos los pasos de su discurso, no es fácil distinguirlos ni alcanzarlo cuando queda la señal mal estampado» (7 de diciembre de 1660). 
como inscripción de la fuente castálida, reúne las figuras de las musas con sus instrumentos y las de Apolo, la Virtud (o la Verdad) y Marte, con el acompańamiento de dos sátiros a ambos lados de la imagen. Al fondo se discierne el monte Parnaso, reconocible por el vuelo de Pegaso, y, debajo de la inscripción, en una especie de hornacina, se ve la imagen de Epicteto, cuyo nombre figura al pie. Esta representación redunda en la entronización parnasiana, pero añade significación moral por vía sutil de colocar a Epicteto como efigie protectora del conjunto. La segunda lámina, que incluye el escudo de armas de Luis Benavides flanqueado por Marte y la Virtud, con sus serpientes gemelas, alude a la naturaleza de la persona a la que van dirigidas las obras, adornada por esas dos grandes categorías de la buena política. La tercera lámina reproduce la imagen de un Quevedo joven, sin lentes, con un rostro bien distinto al que figura en otras ediciones, enmarcado por una cartela que reza «DON FRANCISCO DE QUEVEDO Y VILLEGAS. Cavallero de la orden de Santiago, etc». Nueve ángeles portan la efigie sobre un fondo celestial, mientras otros tres sobrevuelan el aparente traslado. Todos llevan divisas con los nombres de sus obras: San Pablo, Tira la piedra, Vida del tacaño, La cuna, Rómulo, Marco Bruto, Politica de Dios, Los sueños, Fortuna con seso, Doctrina para morir, Virtud militante, Remedios de fortuna. Parece, pues, que el parnaseo pagano de la portada principal que remite a la edición de 1648 se complementa o progresa hacia esta traslación de la figura de Quevedo a manos de estos ángeles, cuyo número, nueve, de forma inevitable, se corresponde con el de las musas del Parnaso clásico. Esta edición de Foppens constituye la piedra fundamental de las ediciones de fin de siglo y no solo corona de laurel al poeta, sino que lo coloca próximo a la esfera celeste, en un movimiento que se consolidará con el paso del tiempo.

\section{Las tres musas últimas castellanas}

Entre 1669 y 1670, al término del privilegio anterior, Foppens publica de nuevo sus tres volúmenes. Mientras procede a tal impresión, el sobrino de Quevedo, Pedro Aldrete, saca a la luz la poesía que faltaba del Parnaso español: en la Imprenta Real se publican en 1670 Las tres musas últimas castellanas..$^{20}$ En la dedicatoria a Pascual de Aragón, arzobispo de Toledo, Aldrete recuerda el paso de este por la universidad salmantina donde él ahora ejerce como Colegial Mayor e indica cómo las obras de su tío «se dirigen a la reformación de costumbres y contienen alta enseñanza». Aldrete hace notar que entre estas composiciones poéticas sobresale lo

20. La edición de Las tres musas reproduce parecida lámina del Parnaso, con las nueve musas a un lado, y al otro, Quevedo coronado por Apolo en medio del paisaje ya conocido de fuente castálida y caballo alado delante de dos elevaciones. En la fe de erratas se señala que el título del libro es el de Segunda parte del Parnaso español, con lo que la continuidad con el libro publicado veintidós años antes estaba asegurada. 
sacro, tal vez pensando en corresponder retóricamente a la protección del primado de España, pero tal vez propagando la imagen de un Quevedo ejemplarizante, de inequívoca piedad cristiana, a pesar de la variedad de géneros que contiene la continuación del Parnaso que publica. ${ }^{21}$ En la primera parte del prólogo Aldrete distingue la producción quevediana entre obras personales y escritos: «supo juntar las prendas naturales en que Dios le adornó con las virtudes católicas, así en sus escritos como en sus obras personales». Más adelante señala: «las obras personales del Autor no fueron inferiores a sus escritos». Entre ambas afirmaciones se desliza la idea de que los escritos son de carácter serio - apoyados por las santas escrituras, los libros de los Padres de la iglesia y los autores de buenas letras- y las obras personales son las composiciones amorosas o las burlescas, si bien escritas con el fin de reprehender los vicios y no las personas. La inclinación de Quevedo hacia este tipo de poemas sirve a Aldrete para reproducir la consigna quevediana en sus palinodias sucesivas de su prosa satírica: que «son verdores traviesos», en la línea tópica habitual de las ineptiae iuveniles o nugae petrarquistas o de tantas otras retractaciones retóricas a mayor gloria de las publicaciones más serias.

Pedro Aldrete traza en este prólogo una breve semblanza de su tío que presenta coincidencias notorias con los datos ofrecidos en la biografía escrita por Pablo de Tarsia. Destaca la insistencia en el catálogo de las obras extraviadas o usurpadas y deja la incógnita de una insatisfacción sobre el resultado final del trabajo de Tarsia: «Otras que no parecen se nombran en el libro de su vida, la cual se escribirá (siendo Dios servido) más por extenso y mejorada de noticias».

En la etopeya de su tío Aldrete ensalza dos elementos, básicos en el elogio retórico: sapientia et fortitudo. La sabiduría, ejemplificada en la lectura constante de libros y reforzada con el relato de dos anécdotas que se hallan también en la biografía de Tarsia: la de la mesa portátil a los pies de la cama que se acerca para que pueda escribir y la de la mesa con dos tornos para el camino para poder comer y leer al mismo tiempo. La fortaleza, en un sentido estoico del término, presentada como virtud para soportar las persecuciones o las dificultades de la vida. Tales virtudes se cifran en episodios — como el de escribir las poesías más burlescas en el destierro de la Torre de Juan Abad o en la prisión de san Marcos de León-o en comportamientos admirables ante la adversidad, incluso ante la inminencia de la muerte.

21. La publicación de esta obra hizo reaccionar de inmediato a Foppens, quien añadió, a los tres volúmenes que había ido editando durante los ańos anteriores, este nuevo con el título de Las tres musas en 1671: logró así, aunque en dos tomos contiguos, reunir por primera vez la obra poética quevediana. La edición de Foppens parece corregida con criterio o, al menos, con voluntad de mejora, ya que modifica la ubicación de ciertos poemas, como el Poema heroico de las necedades y locuras de Orlando el enamorado, que se cambia de Urania, la musa religiosa, para el final de Euterpe donde se contienen, entre otros, los romances burlescos. El escaso tiempo entre ambas ediciones no fue óbice para que el impresor neerlandés cumpliese con su declarado rigor por la edición limpia y depurada de errores. 
La doctrina estoica que difundió Quevedo en sus escritos se compadece, según su sobrino, con sus acciones. En la construcción de este aspecto de su biografía Pedro Aldrete recuerda dos momentos clave, repetidos a lo largo de los siglos como esenciales en la defensa de Quevedo: la resistencia a la corrupción durante el ejercicio de consejero del Duque de Osuna en el reino de Nápoles (con la prueba de una carta en la que rechaza el cohecho fraudulento contra la hacienda real) y la participación también a las órdenes del virrey de Nápoles en la conjura de Venecia, oculto con un disfraz. Ambos episodios, coincidentes punto por punto con lo relatado por Pablo de Tarsia, han sido controversia entre los historiadores, en especial el segundo, desmontado con datos inequívocos por James O. Crosby, pero muy arraigado en el acervo historiográfico relativo a Quevedo, difícil de eliminar de forma definitiva en la recreación cultural de su imagen. Para ambos casos, Aldrete recurre al ejemplario cristiano: Quevedo se muestra firme en Nápoles ante las tentaciones del dinero, como Eleazaro, que antes de incumplir prefiere perder la vida; y finge en Venecia como el mismo Cristo hizo tras la resurrección con su aparición a dos apóstoles en el camino de Emaús. La semblanza concluye con un relato pormenorizado de sus últimos días, con una destacada distinción de su entereza ante la llegada de la muerte. La imagen del caballero estoico se superpone de nuevo con apreciaciones sobre su rostro fallecido que representa «mejor semblante que vivo" y con un dato que apunta, como había hecho, aunque con mayor precisión, Tarsia, a la hagiografía, al desvelar el extraordinario fenómeno de que «después de diez años enterrado, se vio su cuerpo entero".

Las mismas palabras de Pedro Aldrete se hallan a la cabeza de la edición que los hermanos Verdussen, Henrico y Cornelio, hacen de las Obras en Amberes en 1699. La edición es continuación de la de Foppens, de quien obtienen el privilegio, aunque es llamativo que pasen casi 30 años desde la anterior. ${ }^{22}$ Las marcas construidas por la biografía de Pablo de Tarsia y resumidas por su sobrino para la comprensión de la obra de su tío se consolidan a lo largo del tiempo, ayudadas por la difusión de ambas en los distintos paratextos que acompañan a Quevedo en esta trayectoria editorial.

\section{El cathalogo de las obras de Quevedo}

De 1700 data la primera edición de Providencia de Dios, publicada en Zaragoza en la imprenta de Pasqual Bueno. Va encabezada con la dedicatoria del impresor a Juan Luis López, del Consejo de su Majestad y Regente en el Sacro y Supremo de

22. Una edición singular de los Sueños publicada en Perpignan por Breffel en 1679 y las dos primeras partes de la edición conocida madrileña, de 1687, en este caso de Santiago Martín Redondo, vendida en la Gerónima Concepción, que lleva la censura de 1644, y dedicada a Alonso Carnero, caballero de Santiago y Regidor de Ávila, interrumpen este prolongado lapsus de tiempo sin ediciones quevedianas. 
los Reinos de la corona de Aragón; en ella se señala la novedad de la edición: «esta, que hasta ahora no habíallegado a la noticia pública, no había tenido los aplausos que merece, siendo entre todas singularísima». En el prólogo del impresor al que leyere se insiste en la particularidad de verla salir por primera vez a la luz pública,

después de más de medio siglo que la escribió y de haber andado oculta todo este tiempo entre envidiosas manos o, al menos, negligentes, con daño común del Teatro Literario y particular del crédito que tan lucido parto de su ingenio puede aumentarle, aunque lo tenga tan adelantado, a su autor.

El interés del prólogo al propósito de la canonización quevediana se halla, sin embargo, en la inclusión de un catálogo:

aunque no las comprenda todas, será por lo menos el más lleno y apurado de todos los que hasta aquí habrás visto. Si le fueres aficionado (pero ¿quién después de casi un siglo de inmortal fama, no ha de serlo?), estimarás el ofrecértelo, que yo contento con ponerlo en tus manos, no quiero exceder en nada de los límites de mi instituto.

En puridad el catálogo es traducción del texto latino de la Bibliotheca Hispana sive Hispanorum de Nicolás Antonio publicada en 1672. ${ }^{23}$ Se advierten en la traslación del impresor interpolaciones procedentes con toda probabilidad de la semblanza de Pedro Aldrete, en particular los pormenores de su fallecimiento y la anécdota del cuerpo aún íntegro tras diez años de enterrado que Nicolás Antonio no precisa. También tiene cuidado en añadir a las obras citadas por Nicolás Antonio las referencias a las impresiones de los ańos 1660, 1669 y 1671 de Bruselas. Traduce el texto, pero añade esa precisión, con indicación además de la página. Es notoria la inclusión de la recién publicadas Las tres musas últimas castellanas y el comentario adicional sobre algunas obras quevedianas. Nicolás Antonio confecciona este catálogo de Quevedo en dos momentos: en la entrada correspondiente del diccionario detalla las obras de Quevedo impresas (con descripciones bibliográficas muy precisas) y en el apartado de adiciones del segundo tomo, Nicolás Antonio incluye aquellas obras que figuran en la biografía de Tarsia como obras perdidas. El editor de Providencia de Dios las trae tal cual, si bien señala que precisamente lo que figura como Tratado de la inmortalidad del alma es lo que él denomina Providencia de Dios.

La catalogación de la obra quevediana se hace, pues, palmaria en estos años: comienza tal vez con la que presenta Tarsia en 1663; continúa con la de Nicolás Antonio en 1672, con una pequeña disensión sobre el orden que las ediciones de Bruselas conocidas proponen; y concluye con esta de Providencia de Dios de 1700. No es inoportuno reparar en esta mecánica canonizadora, quizá la esencial, la que otorga nominalmente su lugar en el «teatro literario». La obra que-

23. Se trata de las páginas 352-354 del tomo I y de las páginas 658-659 del tomo II, correspondiente al capítulo de Addenda et corrigenda. 
vediana se presenta completa desde muy pronto, pero, en un segundo término, se somete a una lista, a un canon, en sentido estricto, a una catalogación, incluso con la incorporación de aquellas obras perdidas o al menos extraviadas por lo que podríamos llamar en modo retórico la negligencia del tiempo. Esta cuestión no es poco relevante: la fama de Quevedo se construye no solo con la numeración y el catálogo de su obra sino con la indicación precisa de lo que falta. Esta cuestión, la inacabada búsqueda de su verdadero opus magnum, será materia, idealizadora si se quiere, de su prestigio.

La entrada de Nicolás Antonio, que ocupa apenas tres páginas, si contamos la addenda, refuerza una serie de elementos del imaginario quevediano. Su pertenencia al estado nobiliario y cortesano, su condición de homo politicus, su servicio a la corona. Sobre su literatura, la dicotomía omnipresente entre lo jocoso y lo serio se convierte en tópico desarrollado con especial insistencia. Puede llamar la atención en el texto de la Biblioteca Hispana Nova su escasa preocupación por señalar su naturaleza religiosa. Es más: resulta llamativa la precisión de que no tuvo interés Quevedo en pertenecer a una escuela o profesar una orden religiosa determinada, sino la de poder elegir de ellas lo que más pudiera enriquecerle. Es observación emparentada con la diversidad de sus conocimientos, pero no deja de parecer extraña, habida cuenta de la particular obsesión de su sobrino Aldrete por colocarlo como humanista cristiano, de honda preocupación estoica.

\section{Las ediciones del primer tercio del siglo XVIII}

En 1702 se publica en Barcelona una edición promovida por la Academia de los Desconfiados. En cinco tomos, la edición en la imprenta Surià respeta las divisiones antiguas, pero ofrece un cuidado especial en su presentación: 1. Obras; 2. Parte segunda; 3. Política de Dios; 4. Parnaso (a cargo de Rafael Figuerò); 5. Las tres musas. Hay una reedición en 1703, pero lo interesante se halla en la dedicatoria del fraile mercedario Miguel Zugarramurdi, Catedrático de Teología. Aunque la principal finalidad de tal discurso es el de ponderar la excelencia de la Academia, no deja de llamar la atención el elogio extraordinario a Quevedo, al que aleja del Parnaso gentil para convertirlo en parte de la bóveda celeste: con las marcas particularmente profundas de la hipérbole, las alabanzas de fray Zugarramurdi parecen continuar la iconografía etérea de la edición de Foppens, en una especie de ascensus ad caelos que se va conformando a lo largo del siglo XviI:

Ya en la primera página acecha en lo grave, nervioso y elocuente del estilo, todo el primor de la mano, de la pluma y del ingenio. Libro se llama el Cielo en las divinas letras: complicabuntur sicut Liber Coeli. Y es libro, sobre tan hermoseado de planetas y luceros, tan misterioso, que por la hoja transparente del primer Orbe ya se traslucen en el octavo firmamento los caracteres de su gran sabiduría, con que toda la armonía que halló Pitágoras en el Libro de los Cielos renace en estas Obras con la armonía de sus cláusulas, que hacen a estos libros plectros de elocuencia. 
Mire el curioso con perspicacia todas estas Obras y hallará que así en lo jocoso como en lo circunspecto ostenta lejos de tan altos fines que eleva al entendimiento, con el desengaño de las defectibilidades del mundo, a la cumbre indefectible de la más superior Esfera, pues sin presunción de altanero Babel, frisan con el Cielo sus nobles documentos.

Si la lengua elocuente deste grande asombro de Sabiduría (Don Francisco de Quevedo) se mira, se hallará que no prueba la nobleza de sus conceptos de la genealogía del barro torpe sino del solar alto de los Cielos.

Destinolo la Divina Providencia para participante de las luces del más soberano Astro, pues supo unir la elocuencia del sol con los vuelos de su pluma y partos discretos de su lengua [...] porque su lengua, sus escritos y su pluma son alas que nos remontan a la esfera de la luz y al trono del desengaño.

El estilo hiperbólico del fraile mercedario no debería ocultar la figuración santificadora de Quevedo en este preliminar que intenta resaltar la excelencia de la, por otro lado, efímera Academia barcelonesa, disuelta tras los episodios de la Guerra de Sucesión española.

En 1713 el editor Manuel Román publica seis tomos en la imprenta de Herederos de Gabriel León, con estos títulos: Primera parte, Segunda parte, Vida y Obras posthumas, Politica de Dios, Parnaso y Las tres musas. En esta edición, expurgada ya según el dictado del índice de 1707, el censor Juan Manuel de Arguedas se extiende con el recuerdo de los episodios que el sobrino de Quevedo ya había contado como ejemplo de estoicismo y de fortaleza ante las adversidades de su tío, con especial celo religioso ante la muerte, así como su conducta intachable en los asuntos terrenales al negar sobornos y deslealtades con la corona. Arguedas recuerda también, en un claro resumen y paráfrasis del texto de Pedro Aldrete, la decisión de Quevedo de depurar su obra poética para que predomine la voz religiosa y ejemplar de sus escritos. No deja tampoco de celebrar este fenómeno de autocensura - con la quema de algunos escritos y el sometimiento voluntario al Tribunal de la Inquisición-, al calor tal vez del expurgatorio cercano de 1707. Tales aplausos conducen a la misma senda trazada durante el siglo XVII de situar a Quevedo en una corona, si no sacra, al menos merecedora de un lugar próximo o semejante, como el propio censor seńala con particular admiración:

No es lo maravilloso que un amigo secular y discreto escriba con desengaño a eclesiásticos doctos y piadosos sino que un caballero noticioso de cuantos gracejos y chistes revolvió su tiempo pueda correr la pluma con tan feliz vuelo en materias tan altamente sagradas que muchos prácticos en la contemplación no las supieran explicar con tanta delicadeza y tanto fruto para las almas.

En 1716 se reeditan Las tres últimas musas castellanas. En 1720 sale reedición del tomo tercero correspondiente a la Vida y Obras posthumas a cargo de Martínez de Casas. En 1724 vuelven a publicarse los seis tomos de la llamada "edición del León», pero en este caso a cargo del librero Francisco Laso. En 1726, en Amberes, será Verdussen quien decida ampliar los tres tomos de su 
edición de 1699 hasta cuatro: dos de prosa, uno con los poemas y otro con la Vida y Obras posthumas. De 1729, justo el mismo en que aparece el Diccionario de Autoridades, son las colecciones de la Hermandad de san Juan Evangelista y de Alonso de Padilla, en un año especialmente fértil en la producción editorial quevediana. En un periodo de unos 30 años, desde la edición de Amberes de Verdussen de 1699, se computan ocho reediciones de la obra completa de Quevedo: las dos de Barcelona (edición y reedición), las cuatro de Madrid (León, Laso, san Juan Evangelista y Padilla) y las dos de Amberes de Verdussen. En el primer tercio del siglo XVIII, Quevedo es, pues, un autor plenamente canonizado, que además ve cómo su obra completa, reunida poco a poco a lo largo del siglo anterior, se acompaña, a partir de 1713, casi como un integrante más, del relato de su vida que Tarsia había escrito cincuenta ańos antes, en una muestra fundamental del profundo sentido orgánico del conjunto y, por ańadidura, de su eminencia jerárquica en el campo de la literatura espańola.

En la edición madrileña que aparece en 1720 en las prensas de Juan Martínez de Casas de la Vida y Obras posthumas, la dedicatoria de la obra completa de Quevedo va destinada de forma excepcional al propio Quevedo: "pocas veces se habrá visto dedicar las Obras de un Autor al Autor mismo que las compuso y estas Obras posthumas de Don Francisco de Quevedo, como singulares en todo, es preciso que lo sean». Las razones que aduce José de Horta, el probable librero de esta edición y el redactor de esta singular dedicatoria «a la felix memoria del insigne español», ${ }^{24}$ sitúan la fama quevediana en el mismo lugar santificado que había venido creando el aparato paratextual de las ediciones del siglo Xviı y la biografía celebrada de Tarsia. Su ubicación primera en el Parnaso, en el año 1648, apenas tres años después de su muerte, refrendada en el aparato efímero que celebraba la llegada de Mariana de Austria, va adquiriendo de forma paulatina rasgos sacros y no es extraño que vaya ocupando su efigie los lugares designados para la santidad:

El autor es difunto y sus Obras son las que viven y vivirán a la eternidad; el autor es muerto al mundo y piadosamente creemos que vive en el Cielo; las obras que acompañan a sus dueños van siguiendo por eterna felicidad o desgracia eterna a quien las hizo: opera enim illorum sequuntur illos. Apoc, 14. Y Obras tan provechosas como estas no nos podemos persuadir que no hayan sido muy bien vistas en aquel tremendo Tribunal de Dios, cuando dejan tanta enseńanza a los que vivimos en el mundo.

La fama que de Quevedo crean los paratextos trasciende el mero universo literario que el parnasianismo puso de moda en la segunda mitad del siglo XviI para convertirse en un autor parangonable a los doctores de la iglesia capaces

24. En las ediciones de estos años se reproduce el texto de José de Horta bajo la firma de los distintos libreros: en la de 1724, son las siglas F.L. (de Francisco Laso); en la de 1729, son las siglas L.H.D.S.J.E., (La Hermandad de San Juan Evangelista), mientras en la otra edición de ese mismo ańo sale con las siglas J. H. originales. 
de ofrecer auxilio moral y piadoso a los que se acercan a sus escritos. Mientras los paratextos difunden esta imagen, los académicos de la lengua, como lectores particulares de Quevedo, irán desmenuzando su creatividad, sacada más que nada de sus obras menores, de sus musas jocosas. El discurso que prepara la recepción de sus escritos intenta ubicarlo canonizado en la esfera celeste mientras las lecturas que buscan describir la lengua que emplea encuentran en su faceta humilde otras formas de construcción del personaje. De esta tensión probablemente nacerán otras formas de construcción de la fama a partir del siglo XVIII: sobre estos ańos de transición del mundo de los Austrias a los Borbones, con la sanción canonizadora objetivable en los tomos de un nuevo y ambicioso diccionario, el imaginario quevediano ofrece estas marcas complejas en las que conviene detenerse para observar con detalle los matices. 
La fama póstuma de Quevedo en los paratextos de sus obras impresas y en la biografía de Pablo de Tarsia 393

\section{Tabla con las ediciones impresas de Francisco de Quevedo}

\begin{tabular}{|c|c|c|c|}
\hline AÑO & TÍTULO & LUGAR & LIBRERO/IMPRENTA \\
\hline \multirow[t]{2}{*}{1648} & Enseñanza entretenida & Madrid & Pedro Coello/ Díaz de la Carrera \\
\hline & Parnaso español & Madrid & Pedro Coello/ Díaz de la Carrera \\
\hline \multirow[t]{2}{*}{1649} & Primera parte Obras & Madrid & Pedro Coello/ Díaz de la Carrera \\
\hline & Parnaso español & Zaragoza & Hospital Real \\
\hline \multirow[t]{3}{*}{1650} & La fortuna con seso y la hora de todos & Zaragoza & Roberto Duport/Pedro Lanaja \\
\hline & Todas las Obras & Madrid & Tomás Alfay/ Díaz de la Carrera \\
\hline & Parnaso español & Madrid & Pedro Coello/ Díaz de la Carrera \\
\hline \multirow[t]{2}{*}{1651} & La hora de todos & Zaragoza & Pedro Escuer/ Juan de Ybar \\
\hline & Virtud militante & Zaragoza & Roberto Duport/ Pedro Lanaja \\
\hline 1655 & Política de Dios & Madrid & Pedro Coello \\
\hline \multirow[t]{2}{*}{1658} & Parte primera de las Obras & Madrid & Mateo de la Bastida/ Melchor Sánchez \\
\hline & Parte segunda de las Obras & Madrid & Mateo de la Bastida/ Melchor Sánchez \\
\hline 1659 & Parnaso español & Madrid & Mateo de la Bastida/ Pablo de Val \\
\hline \multirow[t]{2}{*}{1660} & Parnaso español & Madrid & Mateo de la Bastida/ Pablo de Val \\
\hline & Obras & Bruselas & Foppens \\
\hline \multirow[t]{2}{*}{1661} & Poesías & Bruselas & Foppens \\
\hline & Epicteto y Focilides & Bruselas & Foppens \\
\hline 1662 & Politica de Dios & Madrid & Mateo de la Bastida/ Díaz de la Carrera \\
\hline \multirow[t]{2}{*}{1664} & Parte primera de las Obras & Madrid & Mateo de la Bastida/ Melchor Sánchez \\
\hline & Parte segunda de las Obras & Madrid & Mateo de la Bastida/ Melchor Sánchez \\
\hline \multirow[t]{3}{*}{1666} & Politica de Dios & Madrid & Mateo de la Bastida/ Imprenta Real \\
\hline & Politica de Dios & Madrid & Mateo de la Bastida/ Pablo de Val \\
\hline & Virtud militante & Madrid & Mateo de la Bastida/ Pablo de Val \\
\hline 1668 & Parnaso español (Amuso Cultifragio) & Madrid & Mateo de la Bastida/ Melchor Sánchez \\
\hline 1669 & Obras & Bruselas & Foppens \\
\hline \multirow[t]{4}{*}{1670} & Las tres musas castellanas & Madrid & Mateo de la Bastida/ Imprenta Real \\
\hline & Obras (primera parte) & Bruselas & Foppens \\
\hline & Obras (segunda parte) & Bruselas & Foppens \\
\hline & Poesías (tercera parte) & Bruselas & Foppens \\
\hline 1671 & Las tres musas castellanas & Bruselas & Foppens \\
\hline 1679 & Sueños y discursos & Perpiñán & Breffel \\
\hline \multirow[t]{2}{*}{1687} & Parte primera de las Obras & Madrid & Martín Redondo/ González de Reyes \\
\hline & Parte segunda de las Obras & Madrid & Martín Redondo/ González de Reyes \\
\hline 1699 & Obras (tres tomos) & Amberes & Verdussen \\
\hline 1700 & Providencia de Dios & Zaragoza & Pasqual Bueno \\
\hline 1702 & Obras (cinco tomos) & Barcelona & Surià /Figueró (Parnaso) \\
\hline 1703 & Parnaso & Barcelona & Surià/ Figueró \\
\hline 1713 & Obras (seis tomos) & Madrid & Gabriel de León/ Manuel Román \\
\hline 1716 & Las tres musas castellanas & Madrid & Gabriel de León/ Manuel Román \\
\hline 1720 & Vida y Obras posthumas & Madrid & José de Horta/ Martínez de Casas \\
\hline 1724 & Obras (seis tomos) & Madrid & Laso/ Juan de Ariztia \\
\hline 1726 & Obras (cuatro tomos) & Amberes & Viuda de Verdussen \\
\hline \multirow[t]{3}{*}{1729} & Obras (seis tomos) & Madrid & H. de s. Juan Evangelista/ A. Sanz \\
\hline & Obras (seis tomos) & Madrid & Alonso de Padilla \\
\hline & Vida y Obras posthumas & Madrid & José de Horta/ Juan de Sierra \\
\hline 1729 & Obras & Madrid & Alonso de Padilla \\
\hline
\end{tabular}




\section{Bibliografía}

Candelas Colodrón, Manuel Ángel, «La 'erudición ingeniosa' de González de Salas en los preliminares de la poesía de Quevedo», La Perinola, 7 (2003) 147-189.

Crosby, James O., "La versión manuscrita de La hora de todos", La edición de textos: Actas del I Congreso de Hispanistas del Siglo de Oro, Pablo Jauralde, Dolores Noguera y Alfonso Rey, Londres, Tamesis Books, 1990, 31-41.

DADson, Trevor J., «La difusión de la poesía española impresa en el siglo XVII, Bulletin Hispanique, 113.1 (2011), 13-42.

Escobar Borrego, Francisco J., "A vueltas sobre la tradición retórica en Francisco de Quevedo: la España defendida como monumento propagandístico y de canonización (con un excurso sobre la pervivencia de Quintiliano)», $\mathrm{La}$ Perinola, 16 (2012), 165-185.

García Aguilar, Ignacio, Poesia y edición en el Siglo de Oro, Madrid, Calambur, 2009a.

- (ed.), Tras el canon. La poesía del Barroco tardío, Vigo, Academia del Hispanismo, 2009b.

Gutiérrez, Carlos (ed.), Monográfico de La Perinola, 15 (2011).

Martinengo, Alessandro, "La Vida de Quevedo de Paolo Tarsia: discours et récit», Homenaje a Quevedo. Acta de la II Academia Literaria renacentista, Salamanca, Universidad de Salamanca, 1982, 59-68.

Moll, Jaime, «El proceso de formación de las Obras completas de Quevedo», Homenaje a Eugenio Asensio, Madrid, Gredos, 1980, 321-330.

Noticia del recibimiento y entrada de la reina nuestra señora doña Maria Ana de Austria en la muy noble y leal coronada villa de Madrid (1650).

Rey, Alfonso (ed.), Francisco de Quevedo, Poesía moral (Polimnia), Támesis, Londres, 1992.

Rojo, Guillermo, «Análisis cuantitativo de las citas del Diccionario de Autoridades», Boletín de la Real Academia Española, 94/209 (enero-julio 2014), 137-196.

Schwartz, Lía (ed.), Francisco de Quevedo, La Fortuna con seso y la Hora de todos, en Alfonso Rey, dir., Obras completas en prosa de Quevedo, vol. I, t. II, Madrid, Castalia, 2003.

Tarsia, Pablo de, Memorial a la Católica y Real Majestad el Rey Felipe IV, s.l, s.n, s.a. (1652)

-, Vida de don Francisco de Quevedo y Villegas, ed. facsímil de la edición de 1663, reproducción cuidada por Melquíades Prieto Santiago y prologada por Felipe B. Pedraza, Madrid, Ara Iovis, 1988.

VÉlez SaInz, Julio, El Parnaso español: canon, mecenazgo y propaganda en la poesía del Siglo de Oro, Madrid, Visor, 2006. 